\title{
PENGARUH SISTEM ANTRIAN DAN PELAYANAN DALAM MENINGKATKAN EFEKTTIFITAS PELAYANAN PASIEN RAWAT JALAN DI PUSKESMAS MADISING NA MARIO KOTA PAREPARE
}

\author{
The Effect of Queue and Service Systems in Improving the Effectiveness of Outpatient Services at \\ Madising Na Mario Health Centres Parepare City \\ Santi Milanda, Usman, Darmawan Ukkas \\ (Program Studi Kesehatan Masyarakat Fakultas Ilmu Kesehatan Universitas Muhammadiyah \\ Parepare) \\ (milandasanti@gmail.com)
}

\begin{abstract}
ABSTRAK
Loket pendaftaran pasien menjadi ujung tombak pelayanan rawat jalan karena merupakan pelayanan pertama dan secara langsung berinteraksi dengan pasien, sehingga dapat memberikan kesan kepada pasien terhadap mutu pelayanan secara umum. pelayanan yang diberikan di loket pendaftaran belum optimal, maka menimbulkan waktu tunggu yang lama kepada pasien, kondisi ini dapat memicu rendahnya kepuasan pasien. Pada masalah ini, aspek cepat dan tepat sangat diperhitungkan dalam penyelenggaraan jasa pelayanan, artinya membiarkan konsumen menunggu tanpa alasan yang jelas akan menyebabkan persepsi yang negatif dalam mutu atau kualitas pelayanan. Rendahnya mutu pelayanan pada suatu puskesmas akan berkaitan dengan citra puskesmas sekaligus penentu terhadap pemanfaatan ulang pelayanannya. Tujuan penelitian adalah untuk mengetahui sistem antrian dan pelayanan dalam meningkatkan efektifitas pelayanan pasien rawat jalan. Metode yang digunakan penelitian survey analitik dengan pendekatan cross sectional study. Teknik pengambilan Accidental Random Sampling dengan jumlah sampel 100 orang yang berobat ke Puskesmas Madising Na Mario Kota Parepare. Hasil penelitian berdasarkan hasil uji statistic dengan menggunakan chi square, maka diperoleh $\mathrm{p}$ (value) $=0,03$ untuk sistem antrian dan untuk pelayanan diperoleh $\mathrm{p}$ (value) $=0,04$. Kesimpulan penelitian adalah ada pengaruh sistem antrian dan pelayanan dalam meningkatkan efektifitas pelayanan pasien rawat jalan di Puskesmas Madising Na Mario Kota Parepare.
\end{abstract}

Kata kunci : Sistem antrian, pelayanan, efektifitas pelayanan

\section{ABSTRACT}

Patient registration counter is the spearhead of outpatient services because it is the first service and directly interacts with patients, so that it can give an impression to patients on the quality of service in general. The service provided at the registration counter is not optimal, so it causes a long waiting time for the patient, this condition can trigger low patient satisfaction. In this problem, the quick and pricese aspects are taken into account in service delivery, meaning that letting consumers wait for no apparent reason will lead to negative perpections of quality or sevice quality. The low quality of service at a Health center will be related to the image of the Health center as well as a determinant of the reuse of its services.

The results of the study based on the results of statistical tests using chi square, then obtained $p($ value $)=0.03$ for the queuing system and for services obtained $p($ value $)=0.04$. The conclusion of the study is that there is an effect of the queuing system in improving the effectiveness of outpatient services and there is an effect of service in increasing the effectiveness of outpatient services at Madising Na Health Center Mario Parepare city.

Keywords: Queuing system, service, service effectiveness 



\section{PENDAHULUAN}

Pembangunan kesehatan menurut Undang-Undang Nomor 25 Tahun 2014 tentang sistem perencanaan pembangunan nasional, bertujuan untuk meningkatkan kesadaran, kemauan, dan kemampuan hidup sehat bagi setiap orang, supaya terwujud derajat kesehatan warga masyarakat yang setinggi-tingginya, sebagai investasi bagi pembagunan SDM (Sumber Daya Manusia) yang produktif secara sosial dan ekonomis.

\section{Pusat Kesehatan Masyarakat} (Puskesmas) adalah unit pelaksana teknis Dinas Kesehatan Kabupaten/Kota yang bertanggung jawab menyelenggarakan pembagunan kesehatan disuatu wilayah kerja. Secara nasional standar wilayah Puskesmas adalah satu Kecamatan. Apabila disuatu Kecamatan lebih dari satu Puskesmas, maka tanggung jawab wilayah kerja dibagi antar Puskesmas dengan memperlihatkan kemampuan wilayah desa/kelurahan atau dusun. ${ }^{1}$

Tujuan pembangunan kesehatan yang diselenggarakan di Puskesmas untuk mewujudkan masyarakat yang memiliki perilaku sehat yang meliputi kesadaran, kemauan, dan kemampuan hidup sehat, mampu menjangkau pelayanan kesehatan bermutu, hidup dalam lingkungan sehat, memiliki derajat kesehatan yang optimal baik individu, keluarga, kelompok dan masyarakat. $^{2}$

Loket pendaftaran pasien merupakan sub jenis pelayanan front office yang menjadi ujung tombak pelayanan rawat jalan karena merupakan pelayanan pertama dan secara langsung berinteraksi dengan pasien, sehingga dapat memberikan kesan kepada pasien terhadap mutu pelayanan secara umum.

Apabila pelayanan yang diberikan di loket pendaftaran belum optimal, sehingga terjadi antrian dan menimbulkan waktu tunggu yang lama kepada pasien, maka kondisi ini dapat memicu rendahnya kepuasan pasien. Pada masalah ini, aspek cepat dan tepat sangat diperhitungkan dalam penyelenggaraan jasa pelayanan, yang artinya membiarkan konsumen menunggu tanpa alasan yang jelas akan menyebabkan persepsi yang negatif dalam mutu atau kualitas pelayanan. ${ }^{3}$

Pada saat ini pasien yang berobat sangat meningkat, dimana mereka hanya dilayani oleh 2 (dua) sampai 4 (empat) orang pegawai, sehingga dapat menyebabkan antrian yang panjang dan menimbulkan lamanya waktu pelayanan serta pegawai menjadi kewalahan dalam melayani setiap pasien, sehingga kadangkala fasilitas yang ada di Puskesmas digunakan pasien terutama tempat duduk tidak mencukupi, banyak pasien yang berobat mengantri sambil berdiri. Pemicu lain dari lamanya proses antrian yaitu untuk poli yang ditujuh, dimana keterlambatan tersebut disebabkan oleh keterlambatan petugas mengantarkan file ke poli klinik, serta jadwal dokter yang terlalu padat.

Maka dari itu penulis bermaksud mengadakan penelitian tentang "Pengaruh 
Sistem Antrian dan Pelayanan dalam Meningkatkan Efektifitas Pelayanan Pasien Rawat Jalan di Puskesmas Madising Na Mario Kota Parepare".

Tujuan dari penelitian ini adalah untuk mengetahui sistem antrian dan pelayanan dalam meningkatkan efektifitas pelayanan pasien rawat jalan di Puskesmas Madising Na Mario Kota Parepare.

\section{BAHAN DAN METODE}

Penelitian ini dengan metode survei deskriptif yang dilakukan di Puskesmas Madising $\mathrm{Na}$ Mario Kota Parepare menggunakan kuesioner yang diberikan ke sampel yaitu 100 responden yang ditentukan dengan teknik Accidental Sampling. Variabel independen dalam penelitian ini adalah sistem antrian dan pelayanan sedangkan variabel dependennya adalah efektifitas pelayanan.

Data primer dalam penelitian ini diperoleh diperoleh berdasarkan jawaban kuesioner menurut variabel yang diteliti sedangkan data sekunder diperoleh melalui pengambilan data di Puskesmas Madising Na Mario Kota Parepare terkait jumlah pasien rawat jalan pada tahun 2017. Data yang telah diolah didapatkan bahwa sistem antrian dan pelayanan yang diberikan di Puskesmas Madising Na Mario Kota Parepare sudah baik dan dikataakan sudah efektif .

\section{HASIL}

Hasil penelitian didapatkan bahwa karakteristik responden berdasarkan kelompok umur (Tabel 1) dominan pada umur 26 - 35 tahun yaitu sebanyak 25 responden (25\%) dan umur terendah $76-85$ tahun sebanyak 3 responden (3\%). Distribusi responden berdasarkan jenis kelamin (Tabel 2), diperoleh jenis kelamin tertinggi lakilaki sebanyak 70 responden (70\%), dan terendah perempuan sebanyak 30 responden (30\%). Untuk tingkat pendidikan tersaji Tabel 3 diperoleh tingkat pendidikan responden yang tertinggi pada pasien dengan tingkat pendidikan terakhir SMA sebanyak 58 responden (58\%) dan terendah SD sebanyak 5 responden (5\%).

Distribusi pengaruh sistem antrian dengan efektifitas pelayanan pasien rawat jalan pada Tabel 4 menunjukkan bahwa sistem antrian yang mengatakan baik sebanyak 97 responden (97\%) sebanyak 3 responden $(3,0 \%)$ dengan sistem antrian kurang baik mengatakan efektifitas pelayanan sudah efektif, sebanyak 2 responden $(2,0 \%)$ dan sebanyak 1 responden $(1,0 \%)$ mengatakan efektifitas pelayanan kurang efektif. Berdasarkan hasil uji statistic dengan menggunakan chi square, maka diperoleh $p$ (value $)=0,03<0,05$ yang menunjukkan bahwa ada pengaruh sistem antrian dengan efektifitas pelayanan.

Distribusi pengaruh pelayanan dengan efektifitas pelayanan pasien rawat jalan pada Tabel 5 menunjukkan bahwa sebanyak 96 responden $(96,0 \%)$ dengan Pelayanan baik mengatakan efektifitas pelayanan sudah efektif. Pelayanan kurang baik sebanyak 4 responden $(4,0 \%)$ mengatakan efektifitas 
pelayanan sudah efektif sebanyak 3 orang $(3,0 \%)$ dan efektifitas pelayanan kurang efektif sebanyak 1 responden $(1,0 \%)$. Berdasarkan hasil uji statistic dengan menggunakan chi square, maka diperoleh $\mathrm{p}$ (value $)=0,04<0,05$, yang menunjukkan bahwa ada pengaruh antara Pelayanan dengan efektifitas pelayanan.

\section{PEMBAHASAN}

Proses antrian merupakan suatu proses yang berhubungan dengan kedatangan pasien pada suatu fasilitas pelayanan kemudian menunggu dalam baris antrian jika belum dapat dilayani dan akan meninggalkan fasilitas pelayanan apabila telah selesai dilayani.

Pelaksanaan penelitian ini ditetapkan 100 responden, dimana dari 100 kuesioner yang dibagikan atau yang telah di isi oleh responden diperoleh jawaban responden menunjukkan bahwa sebanyak 97 responden $(97,0 \%)$ dengan sistem antrian baik mengatakan bahwa sudah efektif, sebanyak 3 responden $(3,0 \%)$ dengan sistem antrian kurang baik mengatakan efektifitas pelayanan kurang efektif.

Berdasarkan hasil uji statistic dengan menggunakan chi square, maka diperoleh $\mathrm{p}$ (value) $=0,04<0,05$, yang menunjukkan bahwa ada pengaruh antara Pelayanan dengan efektifitas pelayanan. Berdasarkan interpretasi tersebut sistem antrian di Puskesmas Madising $\mathrm{Na}$ Mario Kota Parepare bisa dikatakan baik berdasarkan hasil dari beberapa jawaban responden menyatakan bahwa jadwal pelayanan, proses pendaftaran, waktu tunggu dan kejelasan alur pelayanan yang diberikan di Puskesmas sudah baik walaupun berapa responden menganggap sarana dan prasarana yang tersedia di Puskesmas masih perlu penambahan agar pada saat terjadi proses antrian pasien tidak menumpuk sehingga pasien yang ingin berobat tidak perlu lagi berdiri untuk menunggu giliran pada saat ingin melakukan pemeriksaan, tetapi hal ini tidak berpengaruh karena dari jawaban responden banyak yang mengatakan sistem antrian yang ada di Puskesmas sudah baik sehingga dapat disimpulkan bahwa sistem antrian yang terjadi di Puskesmas Madising Na Mario Kota Parepare dalam pelayanan pasien rawat jalan Tahun 2018 sudah dikatakan efektif.

Hasil Penelitian menyatakan bahwa responden yang berpendapat sistem antrian yang baik maka responden akan merasakan kepuasan dalam mendapatkan pelayanan dan salah satu alat ukur untuk mengetahui efektif tidaknya suatu pelayan dalam sistem antrian dapat dilihat dari tingkat kepuasan pasien. Hasil penelitian ini sejalan dengan Penelitian Herman (2016) di Puskesmas Lambasada Kabupaten Donggala dengan judul penelitian Hubungan Kualitas Pelayanan Kesehatan dengan Kepuasan Pasien Rawat Jalan di Puskesmas Lembasada Kabupatten Donggala dengan hasil analisis menggunakan uji chi square yang dilakukan terhadap kualitas pelayanan ketepatan waktu dalam antrian dengan kepuasan pasien, di dapatkan hasil nilai $\mathrm{p}=0,004<0.05$ yang 
menunjukkan bahwa ada hubungan kualitas pelayanan ketepatan waktu antrian dengan kepuasan pasien di Puskesmas Lembasada Kebupaten Donggala karena waktu yang digunakan dalam antrian dalam mendapatkan pelayanan kesehatan tidak menghabiskan waktu lama. ${ }^{4}$

Pelayanan merupakan cara melayani, membantu, menyikapi, mengurus, menyelesaikan keperluan kebutuhan seorang individu atau kelompok. Kualitas pelayanan yang diberikan kepada masyarakat menentukan kesetiaan masyarakat terhadap instansi yang bersangkutan.

Pelayanan merupakan salah satu faktor dalam sistem antrian, dimana ada periode waktu yang dibutuhkan oleh seorang pelanggan untuk mendapatkan pelayanan. Proses pelayanan mungkin tergantung pada jumlah pelanggan menunggu suatu layanan. Efektif tidaknya suatu pelayanan apabila tujuan atau sasaran yang dikehendaki dapat tercapai sesuai dengan rencana semula dan menimbulkan efek atau dampak terhadap apa yang diinginkan atau diharapkan.

Tingkat efektifitas dapat diukur dengan membandingkan antara rencana atau target yang telah ditentukan dengan hasil yang dicapai, maka usaha atau hasil pekerjaan tersebut itulah yang dikatakan efektif, namun jika usaha atau hasil pekerjaan yang dilakukan tidak tercapai sesuai dengan apa yang direncanakan, maka hal itu dikatakan tidak efektif. ${ }^{5}$

Pelayanan yang berkualitas tentunya tidak terlepas dari kemampuan dan kinerja staf dalam memberikan pelayanan kesehatan kepada pasien, staf puskesmas akan mampu memberikan pelayanan yang baik kepada pasien, tambahan pengetahuan dan keterampilan yang dimiliki oleh pemberi pelayanan menjadi nilai tambah yang diterapkan dalam memberikan pelayanan kesehatan kepada pasien.

Pelayanan kesehatan di Puskesmas dapat dikatakan efektif apabila dalam proses pelayanan kesehatan kepada masyarakat sudah sesuai dengan standar pelayanan kesehatan yang telah di tetapkan dan pelayanan yang diberikan sudah cukup sesuai harapan masyarakat.

Penelitian ini bertujuan untuk mengetahui pengaruh pelayanan dalam meningkatkan efektifitas pelayanan pasien rawat jalan di Puskesmas Madising $\mathrm{Na}$ Mario Kota Parepare, diperoleh jawaban responden menunjukkan bahwa sebanyak 96 responden $(96,0 \%)$ dengan pelayanan baik mengatakan bahwa pengaruh pelayanan dalam meningkatkan efektifitas pelayanan rawat jalan di Puskesmas sudah efektif, sebanyak 4 responden $(4,0 \%)$ dengan pelayanan kurang baik mengatakan efektifitas pelayanan kurang efektif.

Berdasarkan hasil uji statistic dengan menggunakan chi square, maka diperoleh $\mathrm{p}$ (value) $=0,04<0,05$, yang menunjukkan bahwa ada pengaruh Pelayanan dengan Efektifitas pelayanan. Berdasarkan interpretasi Pelayanan di Puskesmas Madising Na Mario Kota Parepare dikatakan baik berdasarkan hasil 
dari beberapa jawaban responden menyatakan bahwa kinerja pegawai yang diberikan di Puskesmas sudah sesuai yang diharapkan dan tidak pernah mempersulit pasien selama dalam pemberian pelayanan sehingga dapat disimpulkan bahwa pelayanan yang terjadi di Puskesmas Madisng Na Mario Kota Parepare dalam pelayanan pasien rawat jalan Tahun 2018 sudah dikatakan efektif.

Sebuah pelayanan dapat dikategorikan efektif apabila masyarakat mendapatkan kemudahan pelayanan dengan prosedur yang singkat, cepat, tepat dan memuaskan, keberhasilan meningkatkan efektifitas pelayanan umumnya ditentukan oleh faktor kemampuan seseorang dalam meningkatkan disiplin kerja setiap pemberi pelayanan.

Hasil penelitian ini sejalan dengan Penelitian Ratnawati (2015) di Puskesmas Ngersep Kota Semarang dengan judul penelitian Hubungan antara Persepsi Mutu Pelayanan dengan Tingkat Kepuasan Pasien KIA Puskesmas Ngersep Kota Semarang dengan hasil analisis menggunakan uji chi square yang di dapatkan hasil nilai $\mathrm{p}=0,000$ $<0.05$ yang menunjukkan adanya hubungan antara pelayanan di Poli KIA dengan tingkat kepuasan pasien dalam meningkatkan efektifitas pelayanan di Puskesmas Ngersep Kota Semarang, dimana pasien di Poli KIA dan Poli-poli yang lain dengan fasilitas dan tingkat kenyamanan yang memuaskan diberikan kepada pasien yang beroat ke Puskesmas Ngersep Kota Semarang. ${ }^{6}$

\section{KESIMPULAN DAN SARAN}

Berdasarkan hasil penelitian yang dilakukan di Puskesmas Madising Na Mario Kota pada tanggal 11 Mei - 25 Juli 2018 dapat disimpulkan bahwa ada pengaruh sistem antrian dan pelayanan dalam meningkatkan efektifitas pelayanan pasien rawat jalan di Puskesmas Madising $\mathrm{Na}$ Mario Kota Parepare. Berdasarkan hasil kesimpulan, Untuk meningkatkan efektifitas pelayanan pada sistem antrian agar lebih mempertahankan tingkat layanan yang memuaskan, pihak sebaiknya tetap mempertahankan kondisi seperti pada jadwal pelayanan yang tepat waktu, pihak Puskesmas Madising Na Mario Kota Parepare perlu secara rutin mengamati pelayanannya agar dapat mempertahankan kelebihan yang ada dan selalu meningkatkan kualitas pelayanan yang masih kurang penilaiannya atau menurut penilaian pasien belum sesuai dengan yang diharapkan oleh pasien, hal ini bisa dilakukan dengan lebih memperhatikan terhadap kebutuhan dan keinginan pasien, peningkatan fasilitas sarana dan prasarana, nyaman, dan kepercayaan serta pelayanan yang dijanjikan secara cepat, akurat dan pasti sehingga akan meningkatkan kepuasan pasien dan untuk masyarakat wilayah kerja Puskesmas Madising Na Mario Kota Parepare agar lebih memperhatikan kesehatan masing-masing individu dalam rangka menjaga dan meningkatkan derajat kesehatan. 


\section{DAFTAR PUSTAKA}

1. [Depkes RI] Departemen Kesehatan Republik Indonesia. Capaian Pembangunan Kesehatan Tahun 2011. Jakarta. [serial online]; 2011. [Diakses pada tanggal 2 Mei 2018] at https://pengertian definisi.com/ pengertian - puskesmas -besertafungsidan kegiatannya/.

2. Pemerintah Republik Indonesia. Undang - Undang Nomor 25 Tahun 2014 tentang Pemerintahan Daerah. Jakarta. [serial online]; 2014. [Diakses pada tanggal 4 Mei 2018] at http:// etd. repository.

ugm.ac.id/downloadfile/99017/potongan/ D32016344694bibliography.pdf.

3. Rahayu. Analisis Antrian Pasien Rawat Inap Berdasarkan Spesialisasi Penyakit di RSUD Dr. Kariadi Semaran. Jurnal Gaussian; 2013.

4. Herman. Hubungan Kualitas Pelayanan Kesehatan dengan Kepuasan Pasien Rawat Jalan di Puskesmas Lembasada Kabupaten Donggala. Donggala. Universitas Tadulako, Fakultas
Kedokteran dan Ilmu Kesehatan. [serial online]; 2016. [Diakses pada tanggal 18 Juli 2018] at jurnal.untad.ac.id/jurnal/index.php/Preve ntif/article/view/5750.

5. Heizer $\mathbf{J}$ and Barry R. Operation Management, 6th edition, Prentice-Hall Inc, New Jersey. [serial online]; 2011. [Diakses pada tanggal 7 Mei 2018] at http://respository.usu.ac.id/bistream/1234 567 89/60620/2/Reference.pdf.

6. Ratnawati L. Hubungan Antara Persepsi Mutu Pelayanan Dengan Tingkat Kepuasan Pasien KIA Puskesmas Ngesrep Kota Semarang. Semarang. Universitas Negeri Semarang, Fakultas Ilmu Keolahragaan. [serial online]; 2015. [Diakses pada tanggal 18 Juli 2018]

http://lib.unnes.ac.id/23495/1/641141111 5.pdf.

7. Usman.Analisis Kinerja Tenaga Kesehatan pada Puskesmas Lapadde Kota Parepare. 2016; Media Kesehatan Masyarakat Indonesia; 12(1): 21-28 


\section{LAMPIRAN}

Tabel 1. Distribusi Responden Berdasarkan Umur Di Puskesmas Madising Na Mario Kota Parepare Tahun 2018

\begin{tabular}{ccc}
\hline Umur & Jumlah $(\mathrm{n})$ & Persentase $(\%)$ \\
\hline $15-25$ & 20 & 20,0 \\
$26-35$ & 25 & 25,0 \\
$36-45$ & 19 & 19,0 \\
$46-55$ & 14 & 14,0 \\
$56-65$ & 10 & 10,0 \\
$66-75$ & 9 & 9,0 \\
$76-85$ & 3 & 3,0 \\
\hline Total & 100 & \\
\hline
\end{tabular}

Tabel 2. Distribusi Responden Berdasarkan Jenis Kelamin di Puskesmas Madising Na Mario Kota Parepare Tahun 2018

\begin{tabular}{lcc}
\hline \multicolumn{1}{c}{ Jenis Kelamin } & Jumlah $(\mathrm{n})$ & Persentase $(\%)$ \\
\hline Laki-laki & 30 & 30,0 \\
Perempuan & 70 & 70,0 \\
\hline Total & 100 & 100,0 \\
\hline
\end{tabular}

Tabel 3. Distribusi Responden Berdasarkan Tingkat Pendidikan Di Puskesmas Madising Na Mario Kota Parepare Tahun 2018

\begin{tabular}{lcc}
\hline \multicolumn{1}{c}{ Tingkat Pendidikan } & Jumlah $(\mathrm{n})$ & Persentase $(\%)$ \\
\hline SD & 5 & 5,0 \\
SMP & 23 & 23,0 \\
SMA/Sederajat & 58 & 58,0 \\
S1 & 14 & 14,0 \\
\hline Total & 100 & 100,0 \\
\hline
\end{tabular}

Tabel 4. Pengaruh Sistem Antrian dengan Efektifitas Pelayanan di Puskesmas Madising Na Mario Kota Parepare Tahun 2018

\begin{tabular}{|c|c|c|c|c|c|c|c|}
\hline \multirow{3}{*}{ Sistem antrian } & \multicolumn{4}{|c|}{ Efektifitas Pelayanan } & \multirow{2}{*}{\multicolumn{2}{|c|}{ Total }} & \multirow{3}{*}{$\begin{array}{c}p \\
\text { value }\end{array}$} \\
\hline & \multicolumn{2}{|c|}{ Efektif } & \multicolumn{2}{|c|}{ Kurang Efektif } & & & \\
\hline & $\mathrm{n}$ & $\%$ & $\mathrm{n}$ & $\%$ & $\mathrm{~N}$ & $\%$ & \\
\hline Baik & 97 & 97,0 & 0 & 0,0 & 97 & 97,0 & \multirow{3}{*}{0,03} \\
\hline Kurang Baik & 2 & 2,0 & 1 & 1,0 & 3 & 3,0 & \\
\hline Total & 99 & 99,0 & 1 & 1,0 & 100 & 100,0 & \\
\hline
\end{tabular}

Sumber : Data Primer 
Tabel 5. Pengaruh Pelayanan dengan Efektifitas Pelayanan di Puskesmas Madising Na Mario Kota Parepare Tahun 2018

\begin{tabular}{|c|c|c|c|c|c|c|c|}
\hline \multirow{3}{*}{ Pelayanan } & \multicolumn{4}{|c|}{ Efektifitas Pelayanan } & \multirow{2}{*}{\multicolumn{2}{|c|}{ Total }} & \multirow{3}{*}{$\begin{array}{c}p \\
\text { value }\end{array}$} \\
\hline & \multicolumn{2}{|c|}{ Efektif } & \multicolumn{2}{|c|}{ Kurang Efektif } & & & \\
\hline & $\mathrm{n}$ & $\%$ & $\mathrm{n}$ & $\%$ & $\mathrm{~N}$ & $\%$ & \\
\hline Baik & 96 & 96,0 & 0 & 0,0 & 96 & 96,0 & \\
\hline Kurang Baik & 3 & 3,0 & 1 & 1,0 & 4 & 4,0 & 0,04 \\
\hline Total & 99 & 99,0 & 1 & 1,0 & 100 & 100,0 & \\
\hline
\end{tabular}

Sumber : Data Primer 